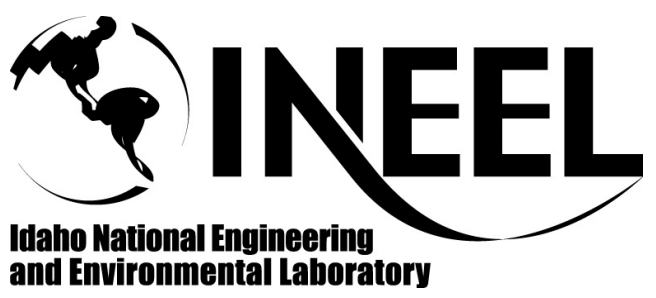

\title{
Adsorption of Lanthanum to Goethite in the Presence of Gluconate
}

S.E. Pepper

L.C. Hull

B.N. Bottenus

S.B. Clark

\section{May 2005}

\section{Goldschmidt Conference}

This is a preprint of a paper intended for publication in a journal or proceedings. Since changes may be made before publication, this preprint should not be cited or reproduced without permission of the author.

This document was prepared as an account of work sponsored by an agency of the United States Government. Neither the United States Government nor any agency thereof, or any of their employees, makes any warranty, expressed or implied, or assumes any legal liability or responsibility for any third party's use, or the results of such use, of any information, apparatus, product or process disclosed in this report, or represents that its use by such third party would not infringe privately owned rights. The views expressed in this paper are not necessarily those of the U.S. Government or the sponsoring agency. 


\title{
Adsorption of lanthanum to goethite in the presence of gluconate
}

\author{
By S. E. Pepper ${ }^{1, *}$, L. C. Hull ${ }^{2}$, B. N. Bottenus ${ }^{1}$ and S. B. Clark \\ 1 Department of Chemistry, Washington State University, Pullman, WA 99164-4630, USA \\ 2 Geosciences Department, Idaho National Laboratory, Idaho Falls. ID 83415-2107, USA \\ (Received May 25, 2005; accepted in revised form December 2, 2005)
}

Summary. We have examined the effect of the gluconate anion, an analogue for cellulose degradation products, on the adsorption of trivalent lanthanum $\left(\mathrm{La}^{3+}\right)^{\mu}$ to goethite. Lanthanum is investigated as an analogue for the trivalent actinides. Batch $\mathrm{pH}$ adsorption edge experiments were used to quantify the adsorption of $\mathrm{La}^{3+}$ in the absence of gluconate and in solutions where gluconate was present at a $1: 1$ mole ratio to lanthanum. Using available thermodynamic data, it is calculated that lanthanum is primarily present in solution as the free $\mathrm{La}^{3+}$ ion at $\mathrm{pH}$ values up to 8.5 in the absence of gluconate. Above $\mathrm{pH} 8.5$, solid $\mathrm{La}(\mathrm{OH})_{3}$ precipitates from solution. In the presence of gluconate, complexation decreases the free $\mathrm{La}^{3+}$ concentration in solution. The fraction of $\mathrm{La}^{3+}$ complexed increases, from $3 \%$ to $50 \%$, as the concentrations of $\mathrm{La}^{3+}$ and gluconate were increased. Very little effect on the adsorption of $\mathrm{La}^{3+}$ to goethite was observed in the presence of gluconate below $\mathrm{pH}$ 7. At $\mathrm{pH}$ values above 7, however, gluconate doubled the maximum amount of $\mathrm{La}^{3+}$ adsorbed when present at concentrations that saturated the gocthite adsorption sites. The presence of gluconate did not appear to inhibit the formation of $\mathrm{La}(\mathrm{OH})_{3}(\mathrm{~s})$ at $\mathrm{pH} 8.5$ and milli molar lanthanum concentrations. Adsorption to the goethite surface was represented with a surface complexation approach using the diffuse double-layer model. Intrinsic binding constants for the surface complexes were estimated from the $\mathrm{pH}$ adsorption edge data using the computer code FITEQL 4.0 and visual curve fitting. Two surface reactions were used to fit the adsorption data in the absence of gluconate: 1) a strong binding site with no proton release and 2) a much higher concentration of weak binding sites with release of two protons per $\mathrm{La}^{3+}$ adsorbed. In the presence of gluconate, a third surface complex was needed that involved a ternary complex of two lanthanum atoms with one gluconate molecule.

\section{Introduction}

In an effort to understand and predict the environmental impact of radioactive waste disposal, it is important to underst and the migration of actinides in the environment. The adsorption of actinides to mineral surfaces is an important part of this since it reduces their mobility in natural systems. The iron (oxyhydr)oxides are arguably the most important minerals because of their large surface areas $[1,2]$ and as

\footnotetext{
* Author for correspondence (E-mail: spepper@wsu.edu).

" $\mathrm{La}^{3+}$ represents the aque ous form of the cation, i.e. $\mathrm{La}^{3+}$ (aq)
}

they are found in most natural media inclucing soils, sediments and rocks. In the context of radioactive waste disposal, they are particularty important because they can be formed as corrosion products of the steet containers commonly used to store radioactive waste materials [3-5].

The iron oxyhydroxide goethite $(\mathrm{FeOOH})$ has been shown to adsorb a wide range of metal ions [6-9], including the actindes and the lanthanides [10-16]. However, liquid and solid radioactive wastes are often associated with organic ligands, such as the products of cellulose degradation, that may affect the mobility of metal ions through the subsurface environment. Potential effects of such ligands include both enhancement and suppression of the adsorption of metal ions onto oxide surfaces. Several different mechanisms have been proposed in the literature by which these processes can occur. The formation of temary surface complexes (surface-metal-ligand or surface-ligand-metal) appears to be one of the most common methods for enhanced metal ion uptake. For example, citric acid has been shown to enhance the adsorption of cadmium to goethite vic the formation of a Cd(II)-citric acid-goethite complex [17]. Similarly, citric acid enhances the adsorption of uranyl at citrate to uranyl ratios of $10: 1$ and $25: 1$ via the formation of a bridged goethite-uranyl-citrate structure [18]. Oxalic acid has been reported to enhance the uptake of cadmium onto a goethite surface by the formation of an oxalate bridge between the cadmium and the mineral surface [19]. The organic acids, phthalic and chelidamic acid enhance $\mathrm{Cu}$ (II) uptake onto goethite via the formation of a ternary surface complex [20]. Other proposed mechanisms for enhancement include the form ation of outer sphere compl exes, such as that seen in the case of lead adsorption to goethite in the presence of EDTA [21], and the formation of insoluble metal-ligand complexes, which may increase the apparent adsorption of metal ions. For example, the presence of the catecholate siderophore derivative, $N$-(2,3-dihydroxy4-(methylamido)benzoyl)-desferri ox amine-B (DFOMTA) caused almost total removal of Eu(III) at neutral to slightly acidic $\mathrm{pH}$ from solution with goethite by the formation of a EU-DFOMTA precipitate [22].

Suppression of metal ion uptake can occur by competition between the ligand and metal ions for surface sites. At intermediate to high $\mathrm{pH}$ values, the sorption of $\mathrm{Eu}$ (III) to goethite is reduced in the presence of humic acid. The authors explained this trend as a competition between surface ligands (from goethite and/or humic acid) and non- 
adsorbed species in solution [23]. Rabung et al. [24] saw a similar trend with Eu(III) on hematite in the presence of humic and fulvic acids. Suppression can also occur by the formation of soluble metal-ligand complexes that are not adsorbed onto the mineral surface. For example, the presence of chelidamic acid reduces the adsorption of calcium to goethite over the $\mathrm{pH}$ range 9 to 11 due to the formation of non-adsorbing $\mathrm{Ca}$ (II)-chelidamic acid solution compl exes [20]. How ever, the effect of organic ligands on metal ion uptake is inconsistent and a complete understanding does not yet exist.

Organic compounds containing cellulose are a component of radioactive waste from materials such as filter paper, wipes and anti-contamination clothing. As cellulosic materials degrade, a wide range of organic compounds are generated. Investigating the effects of cellulose degradation products directly is difficult because these products are complex and may contain many unidentified compounds [25], which makes quantitative evaluation of results difficult. Gluconate can be used as an analogue for water-soluble cellulose degradation products as the carboxyl site on the gluconate molecule reacts similarly to the carboxyl sites on the cellulose products [26]. Gluconate forms a number of stable complexes in aqueous solution with a wide variety of metal cations, including the lanthanides [27-32]. The lanthanides are widely accepted as chemical analogues for the trivalent actinides $[33,34]$, which are found in high-level nuclear waste, have a high specific activity and contribute significantly to the dose emitted from such waste.

Additional work is needed to develop a quantitative understanding of the interaction of trivalent actinide-organic complexes with geologic material. A quantitative treatment is needed to permit prediction of the mobility of these radioactive elements through the environment In this work, we have studied the interaction of lanthanum $\left(\mathrm{La}^{3+}\right)$ complexes with goethite, using gluconate as an anal ogue for organic molecules containing carboxylic acid functional groups. A batch methodology was utilized to explore the partitioning of $\mathrm{La}^{3+}$ to goethite in the absence and presence of the gluconate anion as a function of metal concentration and $\mathrm{pH}$. To provide a quantitative description of the adsorption reactions, the experiments were interpreted by applying the diffuse double layer surface complexation model to the data [35].

\section{Materials and methods}

The adsorption of $\mathrm{La}^{3+}$ to goethite investigated using batch adsorption experiments conducted over a range of $\mathrm{pH}$ and at three different ratios of total dissolved lanthanum to goethite. Experimental results describe a $\mathrm{pH}$ adsorption edge. The adsorption edges were modeled with surface compl exation mass action equations and the diffuse double layer model. Equilibrium constants for the surface complexation reactions were determined by fitting the model to the experimental data.

\section{Lab oratory}

Goethite was prepared according to a modified version of the method described by Schwertmann and Cornell [1].
A solution of ferric chloride was hydrolyzed with potassium hydroxide and heated for 60 hours at $70^{\circ} \mathrm{C}$. The resulting precipitate was washed three times with deionized water and freeze dried. Analysis of the product by powder $\mathrm{X}$-ray diffraction (XRD) showed sharp goethite reflections, with no broadening to indicate the presence of amorphous material. There were no unidentified reflections to suggest other crystalline material was present. The surface area of the goethite was determined to be $33.8 \pm 3.5 \mathrm{~m}^{2} \mathrm{~g}^{-1}$ by the BET method.

A known mass of goethite was suspended in background el ectrolyte ( $\left(0.1 \mathrm{M} \mathrm{KNO}_{3}\right)$ and allowed to hydrate overnight. The reaction was initiated by the addition of $\mathrm{La}^{3+}$ (prepared from $\mathrm{LaCl}_{3}$ ) or by the addition of a $1: 1 \mathrm{~mole}$ ratio of $\mathrm{La}^{3+}$ and gluconate (prepared from sodium gluconate). Three concentrations of $\mathrm{La}^{3+}$, ranging from 0.1 to $10 \mathrm{mM}$, were added either with or without an equivalent concentration of gluconate. The final solid to solution ratio was $0.1 \mathrm{~g}$ per $10 \mathrm{~mL}$ of solution (equivalent to $10 \mathrm{~g} \mathrm{~L}^{-1}$ of goethite). All experiments were prepared in triplicate. An additional experiment was performed at a $\mathrm{La}^{3+}$ concentration of $0.1 \mathrm{mM}$ with a solid to solution ratio of $0.01 \mathrm{~g}$ per $10 \mathrm{~mL}$ of solution (equivalent to $1 \mathrm{~g} \mathrm{~L}^{-1}$ of goethite). Using a surface site density of 2.3 sites $\mathrm{nm}^{-2}[8,36,37]$ with the measured surface area of $33.8 \mathrm{~m}^{2} \mathrm{~g}^{-1}$, the experiments conducted with $10 \mathrm{~g} \mathrm{~L}^{-1}$ of goethite contained approximately $1.3 \mathrm{mM}$ of adsorption sites. The three $\mathrm{La}^{3+}$ concentrations used in these experiments covered a range from approximately 0.1 to 10 times the number of adsorption sites on the goethite surface.

For quality control purposes, initial experiments were conducted to determine the time required to assure $\mathrm{La}^{3+}$ adsorption had reached equilibrium. Blanks and control samples were processed and analyzed to evaluate interferences. Control samples showed that there was no loss of $\mathrm{La}^{3+}$ to the tube walls or to syringe filters. Early experiments showed that 24 hours was stritable to allow uptake to reach a steady state; there was little difference between experiments allowed to run for 24 hours, 48 hours or 1 week.

The $\mathrm{pH}$ of the solutions was adjusted to between 3 and 10 using $\mathrm{NaOH}$ or $\mathrm{HCl}(0.1$ or $1.0 \mathrm{M})$. The $\mathrm{pH}$ was measured at the beginning and end of the experiment, but no attempt was made to control the $\mathrm{pH}$ during the course of the experiment. The $\mathrm{pH}$ was found to deviate by less than 0.5 $\mathrm{pH}$ units over the curation of the experiment. After a period of 24 hours, a portion of the supernatant was withdrawn. This was filtered through a $0.2 \mu \mathrm{m}$ syringe filter and acidified prior to analysis for lanthanum and iron by a Perkin Elmer Optima ICP-OES. Partitioning to the goethite surface was determined by difference from the amount of $\mathrm{La}^{3+}$ remaining in solution Iron was below the detection limit of $5 \mathrm{ppb}$ (approximately $9 \times 10^{-8} \mathrm{M} \mathrm{Fe}$ ) for the ICP-OES in all samples. Under the conditions employed in this study, dissolution of goethite was not detected and therefore the complexation of ferric iron with gluconate was neglected. Several different techniques were attempted to measure the concentration of gluconate in solution and these included ion exchange chromatography, ionization mass spectrometry, high performance liquid chromatography and capillary el ectrophoresis. For all techniques, the concentration of gluconate remaining in solution was either below the detection limit or interferences made quantification impossible. 


\section{Surface complexation modeling}

The goethite surface is amphoteric, resulting in a variability of charge at the mineral surface [36]. The point of zero charge ( $\mathrm{PZC}$ ) is the $\mathrm{pH}$ value at which the total net surface charge is zero. The surface will be predominantly positively charged below the $\mathrm{PZC}$ and predominantly negatively charged above this value [38]. The PZC of goethite has been determined to have a value in the region of $\mathrm{pH} 7.8$ to $8.4[7,39,40]$. For this study, a PZC of 8.0 has been adopted along with the intrinsic constants presented by Tumer and Sassman [41] for the proton reactions with the goethite surface (Table 1).

The uptake of metals by a goethite surface is generally considered to involve either surface complexation or surface precipitation. Surface complexation involves metal cation coordination with surface oxygen atoms and is usually accompanied by the release of protons. This may involve the loss of waters of hydration for the formation of inner sphere complexes or the formation of outer sphere complexes where the adsorbates retain some or all of their solvating water molecul es [38]. Surface precipitation involves the formation of a multilayer phase on the oxide surface. At high sorbate/sorbent ratios, surface precipitation may participate in the total apparent sorption of cations and anions and may even become the dominant sorption mechanism [35]. Differentiation between surface complexation and surface precipitation requires molecular level investigation tools and cannot be accomplished by macroscopic measurements of solution chemistry [42]. Surface precipitation can be incorporated into the surface complexation model by the formation of solid solutions between the sorbing metal hydroxide and the oxide mineral. Alternatively, the aqueous concentration of the metal can be limited by the formation of a separate hydroxide phase and this is the approach used in our models.

Adsorption of metals to oxide surfaces can be described as the formation of surface complexes with specific binding sites on the mineral surface $[35,41]$. The reaction is

Table l. Equilibrium constants for $\mathrm{La}^{3+}$, gluconate, and goethite used in the adsorption model.

\begin{tabular}{|c|c|c|}
\hline Reaction & $\begin{array}{c}\log K @ 25^{\circ} \mathrm{C} \\
(I=0)\end{array}$ & Reference \\
\hline 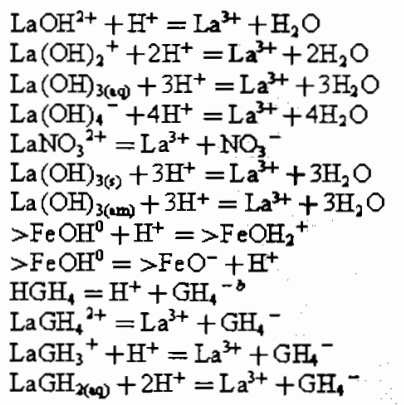 & $\begin{array}{r}8.64 \\
18.17 \\
27.91 \\
40.81 \\
-0.58 \\
20.29 \\
23.49 \\
7.35^{a} \\
-9.17^{\circ} \\
-3.47 \\
-2.91 \\
4.25 \\
11.65\end{array}$ & $\begin{array}{l}{[48]} \\
{[48]} \\
{[48]} \\
{[48]} \\
{[48]} \\
{[44]} \\
{[44]} \\
{[41]} \\
{[41]} \\
{[28]} \\
{[28]} \\
{[28]} \\
{[28]}\end{array}$ \\
\hline
\end{tabular}

a: Protonation/deprotonation constants are assumed to be equal for both strong and weak sites on the goethite surface;

b. Gluconate anion is abbreviated $\mathrm{GH}_{4}$ - representing the four protons on the alcohol groups that can be released when the anion coordi$\mathrm{n}$ ates with a metal ion. described by a mass action expression with an equilibrium constant that is the product of two terms. an intrinsic chemical binding term $\left(X_{\text {int }}\right)$ and a coulombic term. The latter represents the work required to bring an ion from solution through an electrostatic field to the charged mineral surface. There are a number of conceptual models of the electrostatic interaction, and the diffuse double layer model was selected for use.

Dzombak and Morel [35] characterize the iron oxide surface as having a fixed number of adsorption sites in the range of 2 to 3 sites nm ${ }^{-2}$. Strong binding sites represent a small fraction of the total available sites, and weak binding sites comprise the remainder. The ratio of weak to strong sites is estimated to be $40: 1$ [35]. The Dzombak and Morel model is adopted here to describe the goethite surface. Parameters for the formation of surface complexes were estimated using the computer code FITEQL 4.0 [43]. The aqueous speciation model is an important component of the overall equilibrium model between solution and the goethite surface. Equilibrium constants for the aqueous speciation of $\mathrm{La}$ and gluconate used in our calculations are shown in Table 1.

\section{Results and discussion}

The adsorption edges for $\mathrm{La}^{3+}$ on goethite in the absence of gluconate are shown in Fig. 1. Below pH 4, little to no $\mathrm{La}^{3+}$ is sorbed to the goethite surface and is primarily in the aqueous phase. Between $\mathrm{pH} 5$ and 7 , there is a strong adsorption edge, which occurs at a $\mathrm{pH}$ range similar to the range of values reported previously [15]. When the initial $\mathrm{La}^{3+}$ concentration is less than or equal to $1 \mathrm{mM}$, essentially all of the $\mathrm{La}^{3+}$ is adsorbed above pH 7 . This suggests about $1 \mathrm{mM}$ of adsorption sites on the goethite surface in these experiments. At $10 \mathrm{mM}$, the initial amount of $\mathrm{La}^{3+}$ in solution exceeds the number of available adsorption sites and slightly less than $10 \%$ of the $\mathrm{La}^{3+}$ is adsorbed between $\mathrm{pH} 5$ and 7 . This is generally consistent with, though slightly lower than, the number of sites suggested by complete adsorption of $\mathrm{La}^{3+}$ from solutions with $1 \mathrm{mM}$ total dissolved

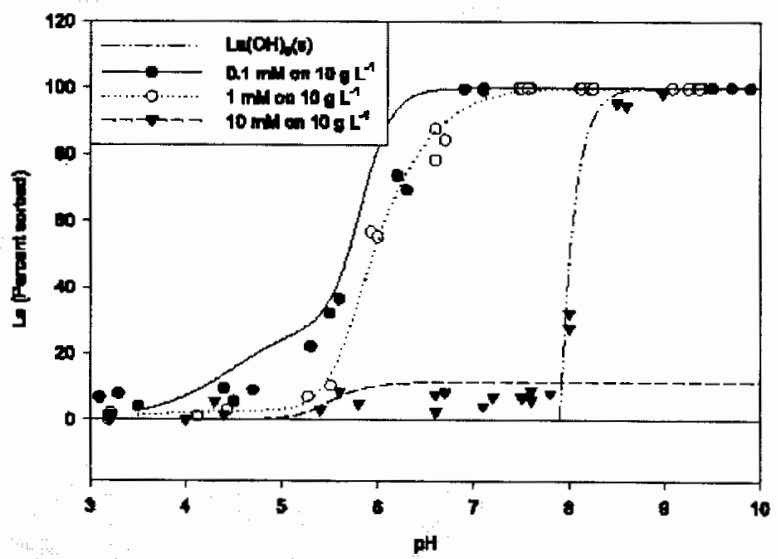

Fig. 1. Adsorption edges for $\mathrm{La}^{3+}$ on $10 \mathrm{~g} \mathrm{~L}^{-1}$ goethite in the absence of gluconate. Points represent experimental results at three different ratios of $\mathrm{La}^{3+}$ to goethite. Lines represent results of modeling the adsorption experiments with adsorption coefficients determined by fitting the experimental data using FITEQL 
lanthanum. At a $\mathrm{pH}$ of approximately 8 , for the experiment with $10 \mathrm{mM}$ lanthanum, $\mathrm{La}^{3+}$ is quantitatively removed from solution. The abrupt removal of lanthanum from solution matches the solubility of $\mathrm{La}(\mathrm{OH})_{3}$ (s) calculated from thermodynamic data [44], indicating that the precipitation of solid La hydroxide is controlling lanthanum in solution under these conditions.

The presence of gluconate does not appear to affect the $\mathrm{pH}$ value at which the adsorption edge occurs. At the lowest $\mathrm{La}^{3+}$ and gluconate concentrations $(0.1 \mathrm{mM})$, there may have been some inhibition of $\mathrm{La}^{3+}$ adsorption below $\mathrm{pH} 5$ (Fig. 2). At a $\mathrm{La}^{3+}$ to goethite ratio of $10 \mathrm{mM} \mathrm{La}^{3+}$ to $10 \mathrm{~g} \mathrm{~L}^{-1}$ goethite, up to $20 \%$ of the $\mathrm{La}^{3+}$ is adsorbed to the goethite. Comparison of Figs. 1 with 2 for $10 \mathrm{mM} \mathrm{La}^{3+}$ between $\mathrm{pH} 7$ and 8 shows that the amount of $\mathrm{La}^{3+}$ adsorbed with gluconate present is approximately twice the amount adsorbed in the absence of gluconate. The amount of $\mathrm{La}^{3+}$ in solution at these concentrations exceeds the number of avail able adsorption sites on the goethite surface. The removal of $\mathrm{La}^{3+}$ by precipitation of $\mathrm{La}(\mathrm{OH})_{3}(\mathrm{~s})$ is the same in both sets of experiments indicating that gluconate at a $1: 1$ mole ratio does not inhibit or enhance the precipitation reaction.

Fendorf and Fendorf [15] reported that at $\mathrm{pH}$ values above the $\mathrm{PZC}$, surface precipitation of $\mathrm{La}^{3+}$ occurred on the goethite surface. The adsorption edge of $\mathrm{La}^{3+}$ occurs below this $\mathrm{pH}$ value and they surmised that $\mathrm{La}^{3+}$ sorption must occur vic a surface complexation mechanism. For the lower metal concentrations used in this study, the sorption trends are consistent with those of Fendorf and Fendorf [15], suggesting that surface compl exation takes place between $\mathrm{pH} 5$ and 7. Surface precipitation appears to occur at a $\mathrm{La}^{3+} \mathrm{con}$ centration of $10 \mathrm{mM}$ above a pH of about 8 .

The presence of gluconate does not appear to affect the sorption of $\mathrm{La}^{3+}$ since the adsorption edges are similar at each concentration. This is contrary to other studies which report that organic complexants generally enhance lanthanide sorption at low pH but reduce sorption at intermediate to high $\mathrm{pH}$ values $[23,45]$. There also does not appear to be a shift in the position of the sorption edge of $\mathrm{La}^{3+}$. This is different from previous studies of metal sorption by

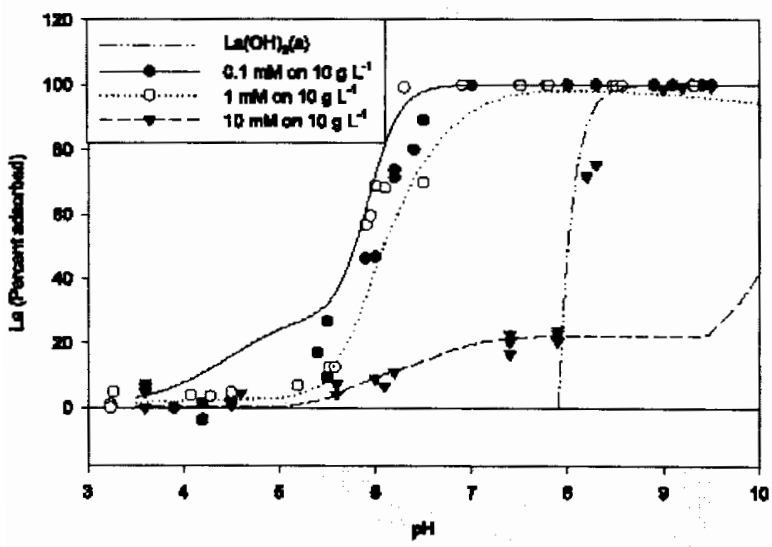

Fig. 2. Adsorption edges for $\mathrm{La}^{3+}$ on $10 \mathrm{~g} \mathrm{~L}^{-1}$ goethite in the presence of gluconate at a $1: 1$ ratio with $\mathrm{La}^{3+}$. Points represent experimental results at three different ratios of $\mathrm{La}^{3+} \mathrm{to}$ goethite. Lines represent results of modeling the adsorption experiments with adsorption coefficients determined by fitting the experimental data using FITEQL. goethite in the presence of anions where the sorption edge shifted to a lower $\mathrm{pH}$ value [46].

\section{Modeling adsorp tion edge experiments}

The first step in modeling the adsorption data was to identify possible surface complexation reactions to include in the model. The number of adsorption sites can be a fitting parameter as part of the surface complexation model development, or can be estimated from independent measurements. As some of the experiments were conducted at $\mathrm{La}^{3+}$ concentrations that exceeded the number of available surface sites, the number of sites was estimated from the maxima measured in the adsorption experiments. The adsorption edge data were then used to estimate $K_{\text {int }}$ values for these adsorption reactions. Based on how well the model matched the experimental data, alternative reactions were evaluated using FITEQL until the residual sum of squares from the fitting exercise was less than about 20 . A generalized mass action expression was written that described the formation of surface complexes on oxide surfaces:

$$
\begin{aligned}
& >\mathrm{FeOH}(\mathrm{s})+\mathrm{Me}^{2+}{ }_{(\mathrm{og})}+(x-1) \mathrm{H}_{2} \mathrm{O}= \\
& >\mathrm{FeO}(\mathrm{OH})_{(x-1)} \mathrm{Me}^{(2-x)+}{ }_{(\mathrm{s})}+(x) \mathrm{H}^{+}
\end{aligned}
$$

The formation of the surface complex usually results in the release of protons. The number of protons released in an adsorption reaction can be estimated using a Kurbatov plot [47]. Rearranging the equilibrium constant expression for Eq. (1) and taking logarithms gives a linear relation between adsorbed metal and $\mathrm{pH}$ :

$$
\log \left(\frac{\left[>\mathrm{FeO}(\mathrm{OH})_{(x-1)} \mathrm{Me}^{(2-x)+}\right]}{[>\mathrm{FeOH}]\left[\mathrm{Me}^{2+}\right]}\right)=x \mathrm{pH}+\log X
$$

$\mathrm{La}^{3+}$ adsorption data are plotted in Fig. 3. At pH values below about 6, the data appear to follow a slope of about 1 (solid line), although a line with a slope of 0 would fit just as satisfactorily. At $\mathrm{pH}$ values between 5 and 7 , the slope is steeper, suggesting two protons are involved in the adsorption reaction (dotted line). At high concentrations of $\mathrm{La}^{3+}(10 \mathrm{mM})$ above $\mathrm{pH} 8$, the slope of approximately 3 and intercept of about -22 (dashed line) are consistent with

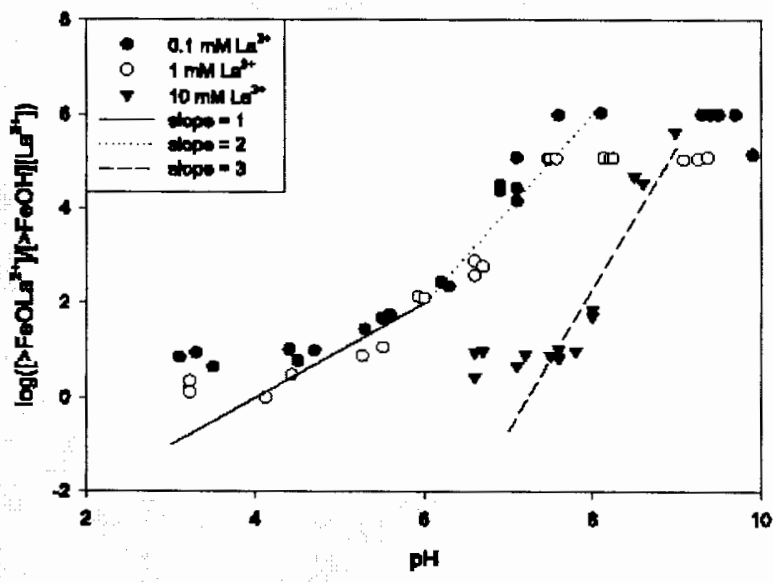

Fig. 3. Kurbatov plot of $\mathrm{La}^{3+}$ adsorption to gaethite 
precipitation of $\mathrm{La}(\mathrm{OH})_{3}(\mathrm{~s})$. From the Kurbatov plot, the initial model of $\mathrm{La}^{3+}$ adsorption is defined with two adsorbed species on two adsorption sites and precipitation of $\mathrm{La}(\mathrm{OH})_{3}(\mathrm{~s})$ :

$$
\begin{aligned}
& >(\text { s }) \mathrm{FeOH}+\mathrm{La} \leftrightarrow>(\mathrm{s}) \mathrm{FeOLa}^{2+}+\mathrm{H}^{+} \\
& >(\mathbf{w}) \mathrm{FeOH}+\mathrm{La}+\mathrm{H}_{2} \mathrm{O} \leftrightarrow>(\mathrm{w}) \mathrm{FeOLaOH}{ }^{+}+2 \mathrm{H}^{+}
\end{aligned}
$$

where $>(\mathrm{s}) \mathrm{FeOH}$ is a strong adsorption site with a $\log K$ of about -4.0 , and $>(\mathrm{w}) \mathrm{FeOH}$ is a weak adsorption site with a $\log K$ of about -10 .

\section{Lanthanum adsorption}

In the absence of gluconate, about $10 \%$ of the $\mathrm{La}^{3+}$ at $10 \mathrm{mM}$ is adsorbed at $\mathrm{pH} 7$. Because essentially all of the $1 \mathrm{an}$ thanum in the $1 \mathrm{mM} \mathrm{La}^{3+}$ experiments is adsorbed to the goethite surface, we conclude that there are approximately $1 \mathrm{mmole}$ of adsorption sites on $10 \mathrm{~g}$ of goethite. This indicates a site density of about $9 \mathrm{mmoles}$ of sites per mole of mineral or 1.78 sites $\mathrm{mm}^{-2}$ using the measured goethite surface area of $33.8 \mathrm{~m}^{2} \mathrm{~g}^{-1}$. Site densities for the goethite were set at $0.25 \mathrm{mmole}$ of sites per mole of mineral for strong binding sites and $10 \mathrm{mmoles}$ of sites per mole of mineral for weak binding sites based on a weak to strong site ratio of $40: 1$ [35]. The number of weak binding sites permits complete adsorption of $1 \mathrm{mM} \mathrm{La}^{3+}$ and is generally consistent with the saturation of all binding sites in the $10 \mathrm{mM}$ adsorption experiment. Protonation constants for the goethite binding sites (Table 1) were taken from Turner and Sassman [41]. Aqueous speciation of $\mathrm{La}^{3+}$ (Fig. 4) was calculated using formation constants for lanthanum hydroxide complexes taken from Haas et $a$ l. [48].

As the precipitation of lanthanum was a possible contributor to removal of $\mathrm{La}^{3+}$ from solution at elevated $\mathrm{pH}$, the data from the adsorption edge experiments were screened using the solubility of $\mathrm{La}(\mathrm{OH})_{3}(\mathrm{~s})$. For each starting $\mathrm{La}^{3+}$ concentration, a $\mathrm{pH}$ was identified above which lanthanum hydroxide precipitation was considered likely. These data

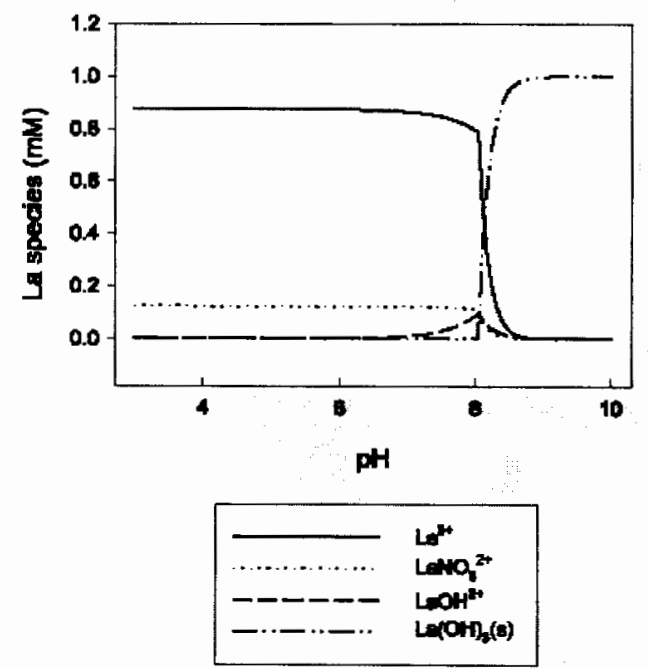

Fig. 4. Speciation diagram for $\mathrm{La}^{3+}$ at $1 \mathrm{mM}$ showing aqueous species and formation of solid $\mathrm{La}(\mathrm{OH})_{3}$ at $\mathrm{pH} 8$. points were removed from the data set used as input to the FITEQL model. Poor fits were obtained for the experimental data using Eqs. (3) and (4), particularly at $\mathrm{pH}$ values below 5. An additional species was added to the model that involved no transfer of protons in the sorption reaction with a $\log K$ of about 12:

$$
>(\mathrm{s}) \mathrm{FeOH}+\mathrm{La} \leftrightarrow>(\mathrm{s}) \mathrm{FeOHLa}
$$

With Eq. (5) included in the model, the residual sum of squares was insensitive to the $\log K_{\text {int }}$ for Eq. (3), indicating the two reactions were redundant. Eq. (3) was dropped from the adsorption model since it resulted in a worse fit than Eq. (5).

From the models of lanthanum adsorption onto goethite, two speci es are important for adsorption. At low $\mathrm{pH}$, adsorption of $\mathrm{La}^{3+}$ is dominated by $\mathrm{Eq}$. (5), with no transfer of protons from the mineral surface. The more commonly considered reaction involving the removal of one proton from the mineral surface did not contribute to a reduction in residual sum of squares and was excluded from the model (Table 2). For adsorption at $10 \mathrm{mM} \mathrm{La}^{3+}$, there was insufficient resolution to quantify $K_{\text {int }}$ for the strong binding site in the model. The very high residual sum of squares for this m odel (Table 2) reflects the discrepancy between the observed maximum adsorption in the batch experiments and the fixed number of weak binding sites based on the experiments at lower $\mathrm{La}^{3+}$ concentrations. $\log K_{\text {int }}$ for the two retained adsorption reactions were cal culated at $I=0 \mathrm{M}$ using the Davies equation [49].

Using Geochemist's Workbench, the adsorption reactions were modeled using the site densities selected by inspection of the adsorption experiment results. $\log K_{\text {int }}$ values in Table 2 were used for the adsorption reactions. The two-site adsorption model provided a very good fit to the adsorption edges in the absence of gluconate (Fig. 1) for adsorption of $0.1 \mathrm{mM}$ and $1 \mathrm{mM} \mathrm{La}^{3+}$ on $10 \mathrm{~g} \mathrm{~L}^{-1}$ goethite. Inclusion of formation of solid $\mathrm{La}(\mathrm{OH})_{3}$ in the model for $10 \mathrm{mM}$ $\mathrm{La}^{3+}$ on $10 \mathrm{~g} \mathrm{~L}^{-1}$ goethite provided a good fit to the laboratory data where adsorption alone significantly underesti-

\begin{tabular}{|c|c|c|c|}
\hline Experiment & $\begin{array}{c}\log K_{\text {ir }} \\
>(\mathrm{s}) \mathrm{FeOHLa} \\
(l=0.1 \mathrm{M})\end{array}$ & $\begin{array}{c}\log K_{\text {mx }} \\
>(w) \mathrm{FeOLaOH}+ \\
(l=0.1 \mathrm{M})\end{array}$ & WRSOS ${ }^{\circ}$ \\
\hline $\begin{array}{l}0.1 \mathrm{mM} \mathrm{La} \text { on } \\
10 \mathrm{~g} \mathrm{~L}^{-1} \text { goethite }\end{array}$ & $10.66 \pm 0.05$ & $-7.41 \pm 0.04$ & 10.83 \\
\hline $\begin{array}{l}1 \mathrm{mM} \text { La on } \\
10 \mathrm{~g} \mathrm{~L}^{-1} \text { goethite }\end{array}$ & $11.46 \pm 0.04$ & $-6.62 \pm 0.01$ & 60.58 \\
\hline $\begin{array}{l}10 \mathrm{mM} \mathrm{La} \text { on } \\
10 \mathrm{~g} \mathrm{~L}^{-1} \text { goethite }\end{array}$ & Not Included & $-10.08 \pm 0.01$ & $2.8 \times 10^{3}$ \\
\hline $\begin{array}{l}0.1 \mathrm{mM} \mathrm{La} \text { on } \\
1 \mathrm{~g} \mathrm{I}^{-1} \text { goethite }\end{array}$ & $14.41 \pm 0.05$ & $-7.09 \pm 0.03$ & 18.16 \\
\hline $\begin{array}{l}\text { Values adopted } \\
\text { recalculated to } \\
I=0 \mathrm{M}\end{array}$ & 12,05 & -6.27 & \\
\hline
\end{tabular}

Table2. Equilibrium constants at jonic strength $(l=0.1 \mathrm{M})$ determined using FITEQL for $\mathrm{La}^{3+}$ adsorption experiments.

a: Weighted residual sum of squares calculated by FITEQL. 
mated $\mathrm{La}^{3+}$ removal from solution above $\mathrm{pH} 8$. The fit was not quite as satisfactory for adsorption of $0.1 \mathrm{mM} \mathrm{La}^{3+}$ on $1 \mathrm{gL}^{-1}$ goethite (not shown). The amount of $\mathrm{La}^{3+}$ adsorbed at low $\mathrm{pH}$ was under estimated for this set of experimental conditions.

\section{Lan th anum adsorption in the presence of gluconate}

To model the effect of gluconate on lanthanum adsorption, speciation of gluconate with $\mathrm{La}^{3+}$ in the solution was added to the aqueous model. Thermodynamic data for deprotonation of gluconic acid as well as constants for formation of gluconate-lanthanum aqueous complexes were obtained from the literature (Table 1) $[28,32,50]$. Data from Giroux et al. [28] were adopted for the deprotonation of the gluconate anion (last four reactions in Table 1). However, the formation of poly-gluconate lanthanum complexes reported by Giroux et al. [28] are not important at the concentrations considered in this study, so were not included in the model. The fraction of $\mathrm{La}^{3+}$ complexed with gluconate depends strongly on concentration, even when the lanthanum gluconate ratio is fixed at $1: 1$. At $0.1 \mathrm{mM}$ (Fig. 5), only a few percent of the $\mathrm{La}^{3+}$ is complexed by gluconate. At $10 \mathrm{mM}$, the fraction of $\mathrm{La}^{3+}$ complexed increased to $50 \%$.

Using the same adsorption reactions and constants as obtained for $\mathrm{La}^{3+}$ adsorption, the $\mathrm{La}^{3+}$ plus gluconate data were modeled using Geochemist's Workbench. Adsorption edge experiments conducted below $10 \mathrm{mM} \mathrm{La}^{3+}$ and gluconate showed little difference in $\mathrm{La}^{3+}$ adsorption. There was less adsorption of $\mathrm{La}^{3+}$ at $0.1 \mathrm{mM}$ with gluconate present than in the absence of gluconate between $\mathrm{pH} 4$ and 5 . However, at higher $\mathrm{La}^{3+}$ concentrations, the gluconate had little effect on adsorption bel ow pH 7. At $10 \mathrm{mM} \mathrm{La}^{3+}$ and gluconate, there was a significant increase in the maximum adsorption density between $\mathrm{pH} 7$ and 8 , with twice the amount of $\mathrm{La}^{3+}$ adsorbed than in the absence of gluconate (Fig. 6).

Fig. 6 shows a comparison between the measured concentration of $\mathrm{La}^{3+}$ remaining in solution after adsorption at $10 \mathrm{mM}$ total lanthanum and glu conate and the residual $\mathrm{La}^{3+}$ predicted from the modeled adsorption using the goethite properties and parameters determined from fitting the $\mathrm{La}^{3+}$ adsorption edges without gluconate present. Two characteristics of this curve bear discussion. Most obvious, the precipitation of $\mathrm{La}(\mathrm{OH})_{3}$ (s) is offset to much higher $\mathrm{pH}$ values in the model because of the formation of lanthanum-gluconate complexes in solution. The complexes in the model reduce the free $\mathrm{La}^{3+}$ activity and prevent $\mathrm{La}(\mathrm{OH})_{3}$ (s) precipitation. However, the measured lab data do not show the change in $\mathrm{pH}$ for $\mathrm{La}(\mathrm{OH})_{3}(\mathrm{~s})$ precipitation. Secondly, while there appears to be a saturation of the anticipated $1 \mathrm{mM}$ of adsorption sites on the goethite surface around $\mathrm{pH} 6$, additional surface adsorption appears to occur between $\mathrm{pH} 7$ and 8 (Fig. 6), reducing the solution $\mathrm{La}^{3+}$ concentration. Based on the $\mathrm{La}^{3+}$ remaining in solution, this appears to be double coverage of the surface sites.

The adsorption model derived for lanthanum in the absence of gluconate fails to match the adsorption data when gluconate is present. Studies of the adsorption of metals in the presence of organic complexing ligands show that

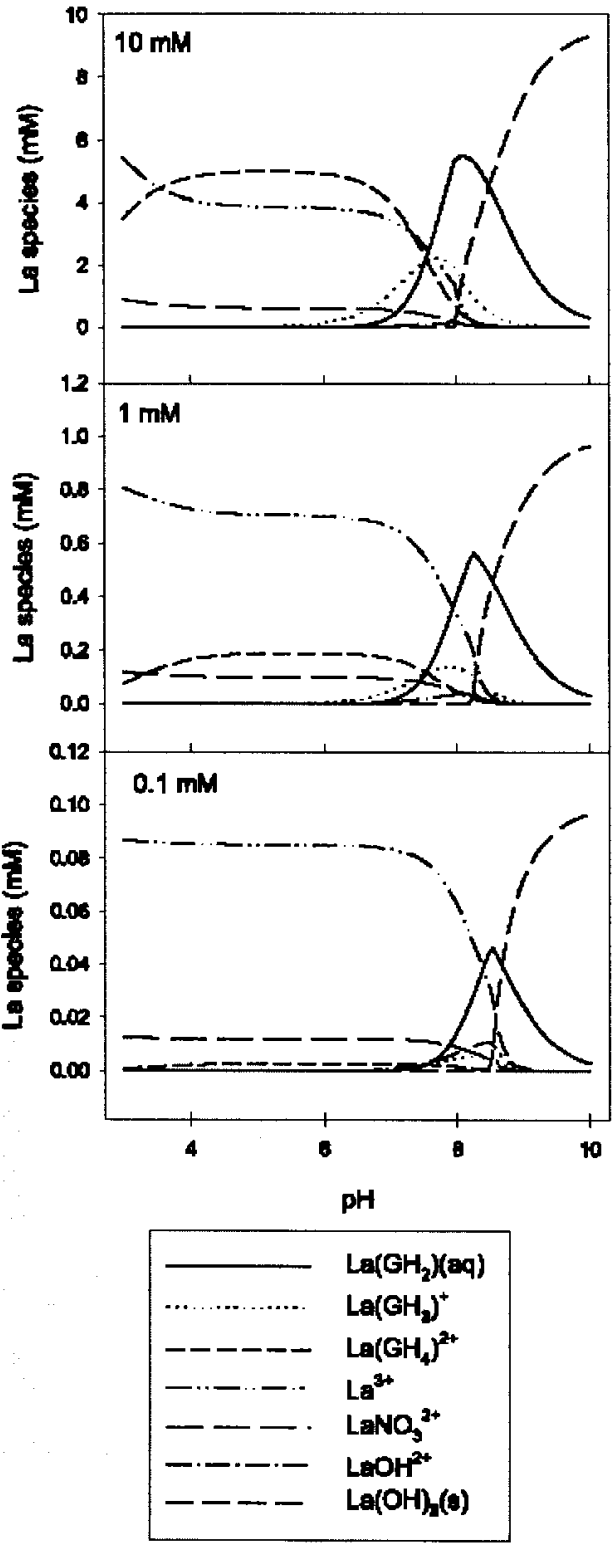

Fig. 5. Distribution of $\mathrm{La}^{3+}$ species and gluconate- $\mathrm{La}$ complexes as a function of $\mathrm{pH}$ for solutions having 3 different concentrations with a 1:1 molar ratio of gluconate to $\mathrm{La}^{3+}$. The decrease in the concentration of $\mathrm{La}(\mathrm{GH})_{2}(\mathrm{aq})$ above $\mathrm{pH} 8.5$ is due to precipitation of solid $\mathrm{La}(\mathrm{OH})_{3}$. The fraction of $\mathrm{La}^{3+}$ complexed with gluconate increases as the total concentration of $\mathrm{La}^{3+}$ and gluconate increases.

the presence of organic ligands affects the adsorption of metals in complex ays $[17,18,45,51]$. In modeling the adsorption of cadmium to goethite, Lackovic et al. [17] found that adsorption to the surface was dominated by the species SOCd+-LCdOH ${ }^{2-}$ above $\mathrm{pH} 7$ where $S$ represents the goethite surface and $L$ represents the citrate ligand [17]. We bypothesized a similar reaction for the adsorption of $\mathrm{La}^{3+}$ to goethite in the presence of gluconate:

$$
\begin{aligned}
& >(\text { w }) \mathrm{FeOH}+2 \mathrm{La}^{3+}+\text { gluconate }^{-}+\mathrm{H}_{2} \mathrm{O} \leftrightarrow \\
& {\left[>(\mathrm{w}) \mathrm{FeOLa}-\left(\mathrm{GH}_{2}\right) \mathrm{LaOH}\right]^{+}+4 \mathrm{H}^{+}}
\end{aligned}
$$




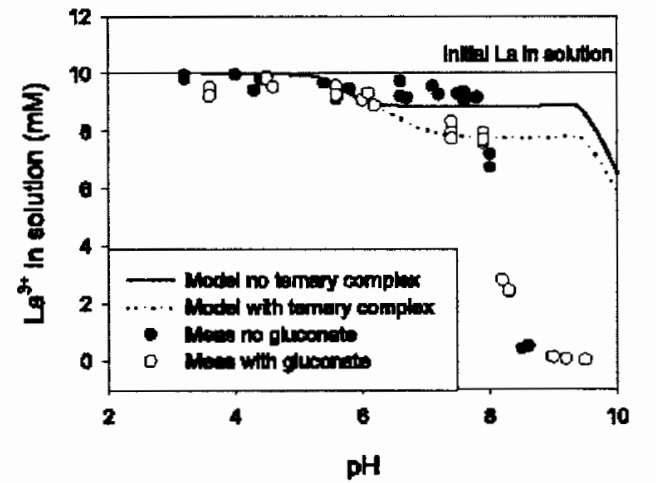

Fig. 6. Comparison of calculated $\mathrm{La}^{3+}$ in solution (lines) with measured $\mathrm{La}^{3+}$ for $10 \mathrm{mM} \mathrm{La}^{3+}$ (filled circles) and $10 \mathrm{mM}$ gluconate plus $\mathrm{Ia}^{3+}$ (open circles) in the presence of $10 \mathrm{~g} \mathrm{I}^{-1}$ goethite.

This reaction involves the binding of an outer sphere lanthanum-gluconate compl ex to an inner sphere lanthanumcomplex. The reaction involves the loss of two additional protons from the alcohol sites on the gluconate anion and is consistent with the predominance of this species at $\mathrm{pH}$ values above 7 (Fig. 5). Because of the significant number of protons transferred during this reaction, it predominantly occurs at elevated $\mathrm{pH}$. There are very little data to attempt to fit an equilibrium constant for the ternary lanthanumgluconate-lanthanum complex and no attempt was made to fit the data using FITEQL. B ased on graphically comparing the fit of the predicted adsorption curve to the measurements (Fig. 6), the $\log K_{\text {int }}$ for Eq. (6) was estimated to be $14 \pm 1$. The uncertainty is based on the amount of change in the $\log K_{\text {int }}$ that produced a visible degradation of the fit of the model to the data. Addition of the ternary complex results in an increase in adsorbed $\mathrm{La}^{3+}$ equivalent to twice the site capacity of the goethite. This is apparent in Fig. 6 where the aqueous phase $\mathrm{La}^{3+}$ concentration has dopped to $8 \mathrm{mM}$. No improvement is achieved in the match above $\mathrm{pH} 8$ where precipitation is presumed to remove $\mathrm{La}^{3+}$ from solution. The distribution of species for the weak surface site on the goethite is shown in Fig. 7 at $0.1 \mathrm{mM}, 1 \mathrm{mM}$, and $10 \mathrm{mM}$. The ternary lanthanum inner sphere-outer sphere complex dominates above $\mathrm{pH} 7$. The significance of the complex decreases as the concentration of $\mathrm{La}^{3+}$ and gluconate in solution is decreased.

The only way to match the removal of $\mathrm{La}^{3+}$ from solution above $\mathrm{pH} 8$ in the $10 \mathrm{mM} \mathrm{La} \mathrm{La}^{3+}$-gluconate experiment was to suppress all lanthanum-gluconate complexes in the aqueous model above $\mathrm{pH} 8$. This is not consistent with the thermodynamic data on lanthanum-gluconate complex formation in the solution phase (Fig. 5). Two possible explanations for this lack of fit are: a) gluconate is strongly adsorbed on the surface of the goethite at $\mathrm{pH} 8$ removing the gluconate from solution or b) the lanthanum-gluconate complex becomes insoluble above pH 8 and precipitates from solution at about the same $\mathrm{pH}$ as $\mathrm{La}(\mathrm{OH})_{3}(\mathrm{~s})$. Giroux et al. [28] reported precipitation of solid lanthanum-gluconate at $\mathrm{pH}$ values around 9 for $1: 1 \mathrm{La}^{3+}$ : gluconate ratios and concentrations in the several mmolar range, similar to concentrations in these experiments. Because the mechanism for this decrease in $\mathrm{La}^{3+}$ above $\mathrm{pH} 8$ in the $10 \mathrm{mM}$ experiment is

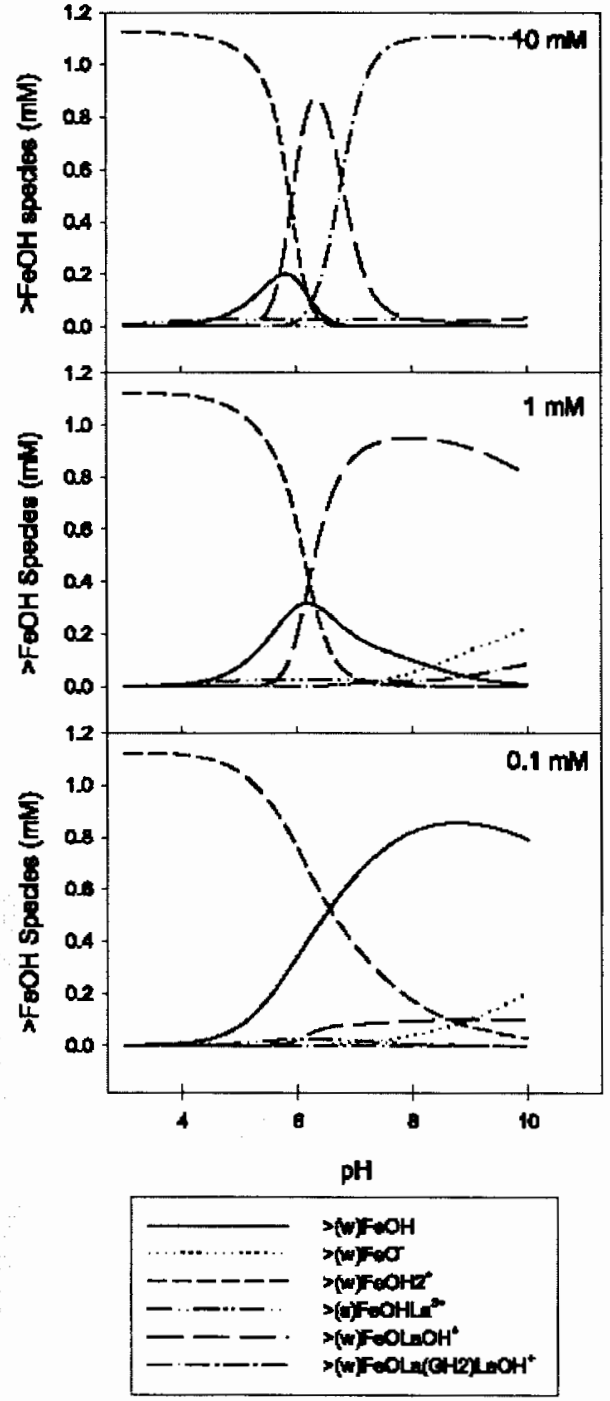

Fig. 7. Distribution of surface species on $10 \mathrm{~g} \mathrm{~L}^{-1}$ goethite $(1.1 \mathrm{mM}$ surface sites) as a function of $\mathrm{pH}$ where $\mathrm{La}^{3+}$ and gluc onate are present at equal concentrations ranging from $0.1 \mathrm{mM}$ to $10 \mathrm{mM}$

unknown, no attempt was made to model the surface precipitation reaction.

\section{Conclusions}

$\mathrm{La}^{3+}$ adsorption in the absence of gluconate was described by a two site adsorption model. At $\mathrm{pH}$ values below 5 , adsorption was to a strong binding site by a reaction that did not transfer any protons. Between pH 5.5 and 7, adsorption increases $\mathrm{La}^{3+}$ binding to a weak site in a reaction that transfers two protons to solution. The addition of gluconate had little effect on the adsorption of $\mathrm{La}^{3+}$ below $\mathrm{pH} 7$. At $\mathrm{La}^{3+}$ concentrations of $0.1 \mathrm{mM}$, there may have been some inhibition of $\mathrm{La}^{3+}$ adsorption bel ow $\mathrm{pH} 5$. Above $\mathrm{pH} 7$, gluconate significantly increased the adsorption of $\mathrm{La}^{3+}$ to goethite. This increase was modeled as a ternary complex which was conceptualized as an outer sphere lanthanum- 
gluconate complex binding to an inner sphere $\mathrm{La}^{3+}$ complex on the surface. Precipitation of solid $\mathrm{La}(\mathrm{OH})_{3}$ was included in the model to account for the quantitative removal of $\mathrm{La}^{3+}$ from solution above $\mathrm{pH} 8$. This removal was unaffected by the addition of gluconate, contrary to the increase in $\mathrm{La}^{3+}$ solubility calculated based on formation of lanthanum. gluconate complexes in solution. The cause of this disagreement is not understood at this time, but may indicate that gluconate is strongly adsorbed to the goethite surface. Currently we are working towards the quantification of gluconate adsorption to goethite and the devel opment of an anion adsorption model for gluconate, as well as investigating other metal-ligand systems with different mineral surfaces.

Results of this investigation indicate that organic ligands can enhance the adsorption of trivalent actinides to iron oxide surfaces. Understanding and quantifying this process is important to predicting their mobility in the environment. Fitting experimental data with particular adsorption equations does not provide a molecular level understanding of reaction processes. Spectroscopic identification of surface species is needed to confirm the species identified by modeling. Use of the models, however, identifies certain types of species and reactions as likely based on the ability of the model to match measured laboratory data and similarities to other analogue chemical systems. Using the results of the model system presented, focused investigations into surface species will be more productive.

Acknowledgment Funding for this work was provided by the U.S. Department of Energy. Environmental Management Sciences Program, and by the Inland Northwest Research Alliance. The authors would al so like to thank $M r$. Paul Gibson for his assistance in analyzing samples by ICP-OES

\section{References}

1. Schwertmann, U., Cornell, R. M: Iron Oxides in the Laboratory: Preparation and Characterization. Weinheim. New York (1991).

2. McBride, M. B.: Environmental Chemsistry of Soils Oxford University Press, New York (1994) p. 51

3. Oh, S. J., Cook, D. C., Townsend, H. E.: Characterization of iron oxides commonly formed as corrosion products on steel. Hyperf. Interact. 112, 59 (1998).

4. Dodge, C. J., Francis, A. J., Gillow, J. B., Hal ada, G. P., Eng, C. Clayton, C. R. Association of uranium with iron oxides typically formed on corroding steel surfaces. Environ. Sci. Technol. 36, 3504 (2002)

5. Eng, C. W., Hal ada, G. P., Francis, A J., Dodge, C. J., Gillow, J B Uranium as sociation with corroding carb on steel surfaces. Surf Interf. Anal. 35, 525 (2003)

6. Spadini, L. Manceau, A., Schindler,P. W. Charlet, L.: Structure and stability of $\mathrm{CA}^{2+}$ surface complexes on ferric oxides. J. Coll Interf. Sci. 168, 73 (1994).

7. Trivedi, P., Axe, L., Dyer, J.: Adsorption of metal ions onto goethite: single-adsorbate and competitive systems. Coll Surf. A 191, 107 (2001)

8. Richter, A., Brendl er, V. Nebelung, C.: Blind prediction of $\mathrm{Cu}(\mathrm{II})$ sorption onto go ethite: current capabilities of diffuse double layer model. Geochim. Cosmochim. Acta 69, 2725 (2005).

9. Johns on, B. B.: Effect of $\mathrm{pH}$, temperature and concentration on the adsorption of cadmium on goethite Environ. Sci. Technol. 24 $112(1990)$.

10. Missana, T., Garcia-Gutierrez, M, Maffiotte, C.: Experimental and modeling study of the uranium(VI) sorption on goethite J. Coll. Interf. Sci. 260, 291 (2003)

11. Combes, J.-M., Chisholm-Brause, C. J., Brown Jr., G. E., Parks, G. A. EXAFS spectroscopic study of neptunium(V) sorption at the $\alpha$-FeOOH/water interface. Ensiron. Sci. Technol. 26, 376 (1992)

12. Tochiyama, O., Endo, S., Inoue, Y.: Sorption of neptunium(V) on various iron oxides and hydrous iron oxides. Radiochim. Acta 68 105 (1995)

13. Moyes, L. N., Parkman, R. H., Charnock, J. M., Vaughan, D. J., Livens, F. R. Hughes, C. R., Braithwaite, A: Uranium uptake from aqueous solution by interaction with goethite, lepidocrocite, muscovite and mackin axwite: an X-ray adsorption spectroscopy study. Environ. Sci Technol 34, 1062 (2000).

14. Sanchez, A. L., Murray, J. W. Sibley, T. H.: The adsorption of plutonium $I V$ and $V$ on goethite. Geochim. Cosmochim. Acta 49 2297 (1985)

15. Fendorf, S., Fendorf, M.: Sorption mechanisms of lanthanum on oxide minerals. Clays Clay Min. 44, 220 (1996).

16. Fukuda, T., Nagasaki. S., Satta, H., Tanaka, S., Suzuki, A., Tanaka, T., Muraoka, S.: Adsorption/desorption of lanthanides on metal oxide surfaces. Radiochim. Acta 82, 239 (1998)

17. Lackovic, K., Angove, M. J., Wells, J. D., Johns on, B. B.: Modeling the adsorption of $\mathrm{Cd}(\Pi)$ onto goethite in the presence of citric acid J. Coll Interf. Sci 269, 37 (2004).

18. Redden, G., Bargar, J., Bencheikh-Latmani, R.: Citrate enhanced uranyl ads orption on goethite: an EXAFS analysis. J. Coll. Interf Sci. 244, 211 (2001).

19. Lamy.I., D jafer, M., Terce, M. Influence of oxalic acid on the adsorption of cadmium at the goethite surface. Water Air Soil Poll $57 / 58,457$ (1991).

20. Ali, M. A., Dzombak, D. A.: Effects of simple organic acids on sorption of $\mathrm{Cu}^{2+}$ and $\mathrm{Ca}^{2+}$ on goethite. Geochim. Cosmochim. Acta 60, 291 (1996)

21. Bargar, J. R, Fersson, P., Brown Jr., G. E.: Outer-sphere adsorption of $\mathrm{Pb}$ (II)EDTA on goethite. Geochim. Cosmochim. Acta 63, 2957 (1999)

22. Kraemer, S. M., Xu, J., Raymond, K. N., Sposito, G.: Adsorption of $\mathrm{Pb}(\mathrm{II})$ and $\mathrm{Eu}(\mathrm{II})$ by oxide minerals in the presence of $n$ atural and synthetic hy drox amate siderophores. Environ. Sci. Technol $36,1287(2002)$.

23. Fairhurst, A. J., Warwick, $P$. The influence of humic acid on europium-mineral interactions. Coll. Surf. A 145, 229 (1998)

24. Rabung, Th., Geckeis, H., Rim, J. I, Beck, H. P.: The influence of anionic ligands in the somption behaviour of $\mathrm{Eu}(\mathrm{III})$ on natural hematite Radiochim. Acta 82, 243 (1998)

25. Glaus, M A, van Loon, L R. Achatz, S. Chodura, A, Fischer, $\mathrm{K}$ : Degradation of cellulosic materials under the alkaline conditions of a cementitious repository for low and intermediate level radioactive waste. Part I: Identification of degradation products. Anal. Chim. Acta 398, 111 (1999).

26. Batton, G. M. N., Berry, J. A, Bond, K. A., Brownsword, M. Linklater, C. M: Effects of organic degradation products on the sorption of actinides. Radiochim. Acta 58/59, 349 (1992).

27. Fialkov, Y. A., Kostromina, N. A.: Gluconic acid complexes of lanthanum. Russ. J. Inorg. Chem. 4, 678 (1959).

28. Giroux, S., Aury, S., Henry, B, Rubini, P.: Complexation of lanthanide(III) ions with polyhydroxy carboxylic acids in aqueous solutions. Eur. J. In org Ohem. 2002, 1162 (2002).

29. Giroux, S., Rubini, D., Henry, B., Aury, S.: Complexes of praseodymium(II) with D-gluconic acid. Polyhedron 19, 1567 (2000).

30. Kostromina, N A: Spectrophotometric and potentiometric determination of the acidic dissociation constants of some rare earth el ement gluconates. Russ. J. Inorg. Chem. 11, 207 (1966).

31. Panda, C., Patnaik, R. K.: Gluc onate complexes of Er(III), Tm(III), $\mathrm{Yb}(\mathrm{III})$ and $\mathrm{Lu}(\mathrm{III})$. J. Indian Chem. Soc. 56, 951 (1979)

32. Sawyer, D. T:- Metal-gluconate complezes. Chem. Rev. 64, 633 (1964)

33. Gschneidner $\mathrm{J}_{\mathrm{r} .}, \mathrm{K}$. A.: Systematics in lanthanide and actinide solids. J. Alloys Compd. 223, 165 (1995)

34. Choppin, G. R. Comparative solution chemistry of the $4 f$ and $5 f$ elements. J. Alloys Compd 223, 174 (1995)

35. Dzombak, D. A., Morel, F. M M.: Surface Complexation Modeling: Hydrous Ferric Oxide. John Whley and Sons, New York (1990)

36. Davis, J. A., Kent, D B.: Surface complex ation modeling in aqueous geoch emistry. Rev. Miner. 23, 177 (1990). 
37. Villalobos, M., Trotz, M. A., Leckie, J. O.: Variability in goethite surface site density: evidence from proton and carbonate sorption. J. Coll Interf. Sci 268, 273 (2003)

38. Robertson, A. P., Leckie, J O.: Cation binding predictions of surface complexation models: effects of $\mathrm{pH}$, ionic strength, cation loading, surface complex, and model fit I. Coll. Interf. Sci. 188 , 444 (1997)

39. Appel, C., Ma, L. Q., Rhue, R. D., Kennelley, E.: Point of zero charge determination in soils and minerals via traditional methods and detection of electroacoustic mobility. Geoderma 113, 77 (2003).

40. Kosmulski, M., Maczka, E., Jartych, E., Rosenholm, J. B.: Synthesis and characterization of goethite and goethite-hematite composite: experimental study and literature study. Adv. Coll. Interf. Sci. $103,57(2003)$

41. Turner, D. R., Sassman, S. A.: Approaches to sorption modeling for high-level waste performance assessment. J. Contam. Hydrol. 21, 311 (1996).

42. Sposito, G.: Distinguishing adsorption from surface precipitation. ACS Symp. Ser. 323, 217 (1986)

43. Herbelin, A. I., Westall, J. C.: FITEQL Version 4.0, a Computer Program for Determination of Chemical Equilibrium Constants from Experimental Data, 99-01. Department of Chemistry, Oregon State University, Corvallis, OR (1999)

44. Spahiu, K., Bruno, J.: A Selected Thermodynamic Database for Rare Earth Elements to Be Used in HLNW Performance Assess- ment Exercises, SKB-95-35. Svensk Karnbranslehantering $A B$, Stockholm, Sweden (1995)

45. Zhenghua, W., Jun, L., Hongyan, G., Xiaorong, W., Chunsheng, Y. Adsorption isotherms of lanthanum to soil constituents and effects of $\mathrm{pH}, \mathrm{EDTA}$, and fulvic acid on adsorption of lanthanum onto goethite and humic acid. Chem. Spec. Bioavail. 13, 75 (2001)

46. Collins, C. R., Ragnarsdottir, K. V., Sherman, D. M.: Effect of inorganic and organic ligands on the mechanism of cadmium sorption to goethite. Geochim. Cosmochim. Acta 63, 2989 (1999)

47. Sinitsyn, V. A., Aja, S. U., Kulik, D. A, Wood, S. A.: Acid-base surface chemistry and sorption of some lanthanides on $\mathrm{K}^{+}$. saturated marblehead illite: I. Results of an experimental investigation. Geochim. Cosmochim. Acta 64, 185 (2000)

48. Haas, J. R., Shock, E. L., Sas sani, D. C.: Rare earth el ements in hydrothermal sy stems: estimates of standard partial molal thermodynamic properties of aqueous complexes of the rare earth elements at high pressures and temperatures. Geochim. Cosmochim. Acta 59, 4329 (1995)

49. Morel, F. M. M.: Principles of Aquatic Chemistry. John Wil ey and Sons, New York (1983)

50. Kostromina, N A. Ion-exchange study of the formation of complexes of lanthanum and gluconic acid. Russ. J. Inorg. Chem. 7 , 806 (1962)

51. Lackovic, K., Angove, M. J., Wells, J. D., Johnson, B. B.: Modeling the adsorption of $\mathrm{Cd}(\mathrm{II})$ onto mul oorina illite and rel ated clay minerals. J. Coll. Interf. Sci. 257, 31 (2003). 